\title{
A EVASÃO ESCOLAR NOS CURSOS SUBSEQUENTES DE ELETROTÉCNICA E EDIFICAÇÕES DO INSTITUTO FEDERAL DE SANTA CATARINA - IFSC - CAMPUS DE CRICIÚMA/SC
}

\author{
THE DROPOUT IN SUBSEQUENT COURSES OF BUILDINGS AND ELECTRICAL \\ ENGINEERING FROM THE FEDERAL INSTITUTE OF SANTA CATARINA - IFSC \\ - CRICIÚMA CAMPUS/SC
}

\author{
SAIS, E. F. ${ }^{1}$ \\ VIEIRA, F.M. ${ }^{2}$
}

\section{Resumo}

O presente artigo apresenta os resultados e reflexões obtidos a partir de uma pesquisa realizada com alunos evadidos dos cursos subsequentes de Edificações e Eletrotécnica do Instituto Federal de Santa Catarina - IFSC - campus de Criciúma/SC, desenvolvida como requisito curricular da disciplina de Estágio em Psicologia da Educação do Curso de Psicologia da UNESC - Universidade do Extremo Sul Catarinense.O trabalho realizado buscou obter uma maior compreensão acerca do fenômeno da evasão, apontado como queixa recorrente relacionada aos cursos citados, visando identificar as principais causas deste fenômeno e suprir a carência de conhecimentos específicos sobre evasão escolar no ensino técnico.Ao fim da pesquisa se pôde constatar como principais fatores atuantes no processo de evasão escolar aqueles ligados a incompatibilidade entre trabalho e estudo (falta de tempo para estudar, baixa renda de problema de transporte) que, mesmo sendo externos a instituição de ensino, podem ser trabalhados se compreendidos em sua totalidade, seja através da Educação à Distância, reforço de vínculo, políticas de assistência estudantil ou formação pedagógica.

Palavras Chave: Educação, Evasão, Ensino Técnico, IFSC.

\section{Abstract}

This article presents the results and reflections obtained from a survey of dropout students in subsequent courses of Buildings and Electrical Engineering from the Instituto Federal de Santa Catarina - IFSC - Criciúma/SC campus, developed as a curricular requirement of the internship in Psychology Education course. The realized work sought a better understanding about the dropout phenomenon, named as recurring complaint on the mentioned courses, to

\footnotetext{
${ }^{1}$ Elenice de Freitas Sais: Graduada em Psicologia pela Universidade da Região da Campanha. Pós-graduada em Didática e Metodologia do Ensino Superior. Mestranda do PPGA - Programa de Pós Graduação em Ciências Ambientais/UNESC. Docente do curso de Psicologia da Universidade do Extremo Sul Catarinense - UNESC. Email: edf@unesc.net

${ }^{2}$ Fabio Martins Vieira: Graduando em Psicologia na UNESC. E-mail: fabiomvieira@gmail.com. Criar Educação, Criciúma, v. 6, nº1, julho/novembro 2016.- PPGE - UNESC
} 
identify the main causes of this phenomenon and supply the lack of specific knowledge about dropouts in technical education.After the research it's possible to list as the main factors of the dropout process those linked to the incompatibility between work and study (lack of time to study, low-income and transportation problems) which, although are outside the educational institution, may be worked if completely understood, either through distance education, strengthening ties with the institution, student aid policies or pedagogical training.

Keywords: Education, Dropout, Technical Education, IFSC.

\section{INTRODUÇÃO}

O presente artigo fora construído a partir de uma pesquisa realizada no Instituto Federal de Santa Catarina - IFSC - campus de Criciúma/SC como requisito curricular da disciplina de Estágio em Psicologia da Educação do Curso de Psicologia da UNESC Universidade do Extremo Sul Catarinense, devido à queixa recorrente de evasão escolar relacionada, principalmente, aos cursos subsequentes de Edificações e Eletrotécnica oferecidos no período noturno pela instituição.

Castro,Dore\& Sales (2013) relatam que, apesar da quantidade razoável de estudos voltados para o tema da evasão escolar, a maior parte destes abrange trabalhos relacionados ao ensino básico e superior. Dore\&Lüscher (2011) apontam a falta de conteúdo teórico e empírico sobre o tema específico, que acaba por dificultar a investigação deste problema dentro do ensino técnico do Brasil.

O artigo em questão estrutura-se trazendo uma discussão acerca da relação entre o trabalho e a evasão escolar -por ter sido este o principal fator causador deste fenômeno na amostra pesquisada - tomando como base a teoria das necessidades de Maslow e a responsabilidade social da instituição considerando sua missão e valores descritos no Plano de Desenvolvimento Institucional (PDI) em questão. Posteriormente seguem apontamentos sobre ferramentas quepodem ser eficazes no combate da evasão escolar, atuando de forma preventiva, compensatória ou facilitadora de permanência e êxito dos alunos. Esta seção faz uma reflexão sobre as políticas de assistência estudantil estratégias pedagógicas aplicáveis ao problema da evasão que são condizentes com a política e a filosofia institucional do IFSC.

\section{TRABALHO, MOTIVAÇÃO E EVASÃO ESCOLAR}

Criar Educação, Criciúma, v. 6, no1, julho/novembro 2016.- PPGE - UNESC 
A problemática da evasão escolar quando ocasionada pela incompatibilidade entre as rotinas de estudo e trabalho pode ser encarada, por algumas pessoas, como uma questão de falta de foco e planejamento ou visão de futuro por parte do estudante, dito como incapaz de compreender os benefícios à longo prazo de uma formação técnica. Porém, LaPlante (2014) apresenta que $81 \%$ dos alunos - participantes de seu projeto "Nenhum Evadido" 3 - que já abandonaram os estudos em algum momento de suas vidas, tem consciência dos reflexos sociais e econômicos que uma formação pode lhes proporcionar.Porém, mais importante do que isto é que se consiga compreender que tal objetivo é alcançável, mesmo com seus devidos desafios e dificuldades, sendo estes sobrepujados pelo apoio de seus colegas e esforço pessoal.

[...] os estudantes evadidos geralmente consideram os desafios complexos, o que torna a escola uma prioridade significativamente menor em suas vidas em relação às suas outras obrigações, o que inclui, mas não se limita, a trabalho, paternidade, segurança pessoal, compromissos legais e cuidados com os membros da família que sofrem com problemas de saúde. (LAPLANTE, 2014, p.2)

Por estes motivos, a influência do trabalho sobre o estudo é colocada em análise como um fator ligado a desmotivação. Toma-se aqui o modelo de hierarquia de necessidades representado na Pirâmide de Maslow, composto pelas necessidades fisiológicas na base do seu esquema, seguidas de forma progressiva pelas necessidades de segurança, posse e amor, estima e auto-realização, (STOLTZ, 2000) como fundamento para compreenssão do funcionamento da motivação humana.

Stoltz (2000) ainda explica que de acordo com tal teoria, quanto mais próximas da base, mais vitais e intensas são as necessidades, enquanto as mais elevadas se apresentam de forma mais sutil e dispensável. No entanto, só é possível galgar um novo degrau quando todos os inferiores estão satisfeitos. Desta forma, a motivação do sujeito está sempre voltada para aquilo de mais básico que Ihe falta.

\footnotetext{
${ }^{3}$ Original: nodropouts. Informações no site: nodropouts.org
}

Criar Educação, Criciúma, v. 6, no1, julho/novembro 2016.- PPGE - UNESC 
De acordo com Maslow (1970) as necessidades mais instintivas como a fome, sede, sexo, sono são prioritárias e devem ser aliviadas periodicamente. Acima destas estão as necessidades por segurança, entrando aqui a segurança financeira propiciada por um emprego, capaz de manter também a segurança pessoal e da família. Apenas quando esta classe secundária se apresenta satisfeita um sujeito demonstra motivação para conquista de amor e respeito, onde passa a desenvolver uma busca menos egoísta envolvendo lealdade, consciência cívica e amizade. Porém, o desenvolvimento da autonomia, confiança, espontaneidade e respeito mútuo que caracterizam o perfil de aluno crítico ideal se tornam indispensáveis apenas no quarto nível desta hierarquia, que precede apenas a busca pela autorealização.

A partir deste ponto de vista, pode-se compreender a prioridade dada ao trabalho em função do estudo, considerando que a troca de uma necessidade básica por outra mais elevada, seria interpretada pelo organismo como uma ameaça catastrófica (MASLOW, 1970). Tal exposição visa levar a reflexão acerca das condições básicas para suprimento das necessidades fisiológicas, de segurança e amor, oferecidas ao cidadão brasileiro como sendo suficientemente efetivas, ou não, para que este se sinta motivado ao desenvolvimento pessoal, social e econômico de seu país.

Simões (2010) fala que o trabalho tem uma importância exacerbada dentro do panorama brasileiro - devido a grande desigualdade social - como tentativa de se adquirir condições mínimas de cidadania. Porém, infelizmente, grande parte da população sofre com baixa qualidade empregatícia e de remuneração, levando boa parcela desta ao mercado informal. Certa dicotomia pode ser percebida na relação entre escola e trabalho no discurso de Simões (2010, p.109):

Por um lado, a escola é parte do aparelho do Estado, contribuindo para reprodução da estrutura de classes por meio da distribuição de jovens pelas variadas funções da força de trabalho com base em suas qualificações educacionais e a reprodução das relações por meio da transmissão ideológica dos valores dominantes. Por outro, a escola é utilizada como estratégia das pessoas em superar as suas condições socioeconômicas mais precárias de vida, como também a aquisição do conhecimento e busca de formação.

Criar Educação, Criciúma, v. 6, nº1, julho/novembro 2016.- PPGE - UNESC 
A missão do Instituto Federal de Santa Catarina (2009, p.9) de "desenvolver e difundir conhecimento científico e tecnológico, formando indivíduos capacitados para o exercício da cidadania e da profissão" pode representar esta dualidade, atuando simultaneamente em prol do mercado e do aluno. Entretanto focalizaremos, no momento, em seu fundamento teórico de "educação como condição de libertação do homem." (IFSC, 2009, p.23), onde o próprio plano de desenvolvimento da instituição afirma que:

Uma instituição educacional deve garantir, aos egressos, condições de exercício de cidadania responsável, capacitação para o trabalho, socialização do conhecimento e da tecnologia, colocando-os a serviço da construção de uma sociedade mais ética, justa e igualitária. (IFSC, 2009, p.24)

A educação deve ser então inclusiva, possibilitando ao sujeito exercer sua cidadania e suprir suas necessidades básicas, para então motivar-se ao crescimento e auto realização.Porém para que tal processo inclusivo ocorra a escola precisa investigar constantemente suas demandas e se adequar as necessidades apresentadas.

\begin{abstract}
Uma concepção de educação inclusiva e solidária requer planejar espaços, tempos e metodologias que considerem os conhecimentos, as potencialidades, as limitações e os ritmos de aprendizagem dos diferentes sujeitos, como condições para construir uma nova cultura escolar, fundada nos valores da democracia, da justiça, da solidariedade e do respeito à diferença, como integrantes da aprendizagem profissional e pessoal. (IFSC, 2009, p.35)
\end{abstract}

Sendo então, que cada comunidade pode apresentar uma necessidade diferente, "para que o Instituto se consolide, cada Campus precisa rever a sua identidade, perguntando-se, constantemente, se o que está fazendo satisfaz às necessidades da comunidade na qual está inserido." (IFSC, 2009, p.26)

Todo este levantamento filosófico acerca da instituição estudada é resgatado para demonstrar sua flexibilidade frente a um novo desafio que, no caso do Instituto Federal de Santa Catarina -campus Criciúma, se refere a evasão escolar ocorrida nos cursos subsequentes de Edificações e Eletrotécnica, com o objetivo de sustentar a ideia de Barbieri et al. (2005, p.954) de que "é necessário rever a estrutura do ensino noturno, adequando-o a realidade dos alunos."

Criar Educação, Criciúma, v. 6, nº1, julho/novembro 2016.- PPGE - UNESC 
A prioridade dada ao trabalho, unida aos problemas de deslocamento e baixa renda relatados por 54,7\% da amostra de alunos evadidos, comprova per se, que a problemática não se origina na instituição. Porém tal fator não extingue a responsabilidade social da escola e sua capacidade de atuação sobre o problema, podendo desenvolver uma série de estratégias preventivas, compensatórias ou facilitadoras de permanência e êxito, como a implementação de políticas adequadas de assistência estudantil, reestruturação curricular com inserção de Educação a Distância, projetos de acompanhamento individual e reforço de vínculo, incentivo à formação pedagógica.

\section{POLÍTICAS DE ASSISTÊNCIA ESTUDANTIL}

Laudares (2009) questiona a efetividade da educação profissional oferecida pela rede de escolas técnicas federais, por estas já apresentarem um índice médio de evasão de $40 \%$ desde o seu primeiro ano de implementação. De acordo com este autor "falta uma política agressiva de geração de suporte para garantir a permanência dos alunos na sala de aula da rede de educação profissional para realização de todo curso." (LAUDARES, 2009, s/p) Pesquisas do mundo inteiro apontam os mesmos indicadores como fatores causadores da evasão escolar, sendo um concenso geral que os fatores sócio-econômicos se apresentam como os de maior influência no processo. (DORE \& LÜSCHER, 2011)

Dados coletados através do censo do Instituto Nacional de Estudos e Pesquisas(INEP / MEC, 2007) demonstram que 57,7\% dos alunos matriculados nos cursos subsequentes de educação profissional possuem entre 20 e 29 anos de idade, sendo este mais um dado condizente com a realidade do IFSC - campus Criciúma. Dore \& Lüscher (2011, p.154) apresentam a ideia de que tal dado faz considerar este perfil de aluno como "trabalhadores em busca de qualificação profissional para ampliar suas oportunidades de inserção no mercado de trabalho e que podem financiar sua qualificação." Porém, paradoxalmente, demonstram em suas pesquisas que a maior taxa de evasão escolar ocorre entre alunos desta mesma faixa etária, sugerindo esta contradição como uma lacuna a ser pesquisada.

Criar Educação, Criciúma, v. 6, no1, julho/novembro 2016.- PPGE - UNESC 
O trabalho apresentado propõe uma análise motivacional sobre tal demanda, compreendendo o abandono dos estudos como uma escolha de prioridades baseada em uma hierarquia de necessidades atuantes na manutenção da saúde física e psicológica de cada sujeito. Utilizando a lógica da "adesão" de Freire (2001, p.58) de que "um pólo não aspira à sua libertação, mas à sua identificação com o pólo oposto", se pode deduzir também que a análise de prioridades de um sujeito pode estar sendo destorcida pela sua identificação com aquilo que o oprime. Sua busca por libertação pode estar voltada para a aquisição individualista e não para a reforma.Uma ideia perfeitamente compreensível considerando a realidade brasileira como um dos países com maior concentração de renda do mundo (ANDIFES, 2010). A ideia de educação libertadora que permeia a filosofia do IFSC visa desconstruir este paradigma, libertando os indivíduos de si mesmos. No entanto, para atingir tal objetivo não deve apenas oferecer ensino gratuíto, mas ser capaz de utilizar, fortalecer e elaborar ferramentas capazes de sustentar o vínculo entre instituição e aluno, sendo uma destas as políticas de assistência estudantil.

Laudares (2009) afirma que para se compreender o aluno e suas necessidades em sua plenitude, este deve ser analisado em sua realidade exterior à escola (família, cultura e economia) e no interior da escola e todo o suporte (material, didáticopedagógico, infra-estrutura) que esta pode lhe oferecer. Por sua vez, o Plano Nacional de Assistência Estudantil (Pnaes) apresenta que estas dificuldades sócioeconômicas são responsáveis por grande parcela da evasão escolar. (ANDIFES, 2010)

Por fim, o Documento de Referência para Assistência Estudantil do Instituto Federal de Educação, Ciência e Tecnologia de Santa Catarina, apresenta as políticas de assistência como um:

[...] conjunto de ações pautadas pelos seguintes princípios: supremacia do atendimento às necessidades socioeconômicas e pedagógicas; universalização da assistência ao estudante; respeito à dignidade do sujeito, à sua autonomia e ao seu direito a benefícios e serviços de qualidade, bem como à convivência escolar e comunitária; igualdade de direito no acesso ao atendimento, sem discriminação de qualquer natureza; equidade no atendimento, visando a diminuição da desigualdade; divulgação ampla dos benefícios, serviços, programas e projetos assistenciais, bem como dos recursos oferecidos pela instituição e dos critérios para seu acesso;

Criar Educação, Criciúma, v. 6, nº1, julho/novembro 2016.- PPGE - UNESC 
participação da comunidade acadêmica nos processos decisórios. (IFSC, $2010, \mathrm{~s} / \mathrm{p})$

De acordo com a resolução estabelecida pelo Colegiado de Ensino, Pesquisa e Extensão CEPE/IFSC no 001/2010 de 30 de novembro de 2010 a assistência estudantil do instituto Federal de Santa Catarina é dividida em duas modalidades de abrangência: o atendimento universal aos estudantes e 0 atendimento aos estudantes com vulnerabilidade social, objetivando, conforme seu art. $2^{\circ}$, "garantir condições de acesso e permanência com êxito dos estudantes no percurso formativo".

Com a revogação da resolução CEPE/IFSC n054 em 17 de fevereiro de 2014, que regulamentava o Programa de Atendimento ao Estudante com Vulnerabilidade Social (PAEVS), a assistência estudantil fica pautada provisoriamente no decreto $\mathrm{n}^{\circ}$ 7.234 de 19 de julho de 2010 que dispõe sobre o Pnaes. De tal forma, prevê-se auxílio financeiro ou material para estudantes com renda per capta menor do que um salário mínimo e meio.Esta nova abordagem caracteriza um grande avanço ao se comparar com a limitação de $1 / 4$ de salário mínimo que era imposta pela resolução de 2011 do PAEVS, tornando o programa muito mais acessível para os alunos dos cursos subsequentes, avaliados com uma renda familiar média ponderada de 3,38 salários mínimos.

Em medida provisória, aprovada pelo Comitê Gestor de Assistência Estudantil, estabeleceu-se um auxílio financeiro que pode variar de $R \$ 100,00$ até $R \$ 400,00$, de acordo com a situação de vulnerabilidade de cada estudante, sendo este, outro aumento considerável ao ser relacionado com o auxílio máximo de $1 / 4$ de salário mínimo proposto pela reolução CEPE/IFSC (2011) n5ㄴ.

Apesar destas melhorias, ainda existe a queixa do baixo número de assistentes sociais e a dificuldade que isto gera no momento de se avaliar cada uma das milhares de solicitações de auxílio, impedindo assim uma análise da integralidade de cada indivíduo, substituída por "simples" análise documental acompanhada por uma breve entrevista.(CEPE/IFSC, 2014)

Além do auxílio financeiro, ficam regulamentados também os Programas de Atendimento Universal, descritos no art. 6ํㅜㅇ sendo eles: Programa de Desenvolvimento Técnico-Científico, Programa de Saúde e Apoio Psicossocial, Criar Educação, Criciúma, v. 6, nº1, julho/novembro 2016.- PPGE - UNESC 
Programa de Acompanhamento Acadêmico e Suporte ao Ensino, Programa Cultura, Arte e Esporte, Programa de Incentivo à Participação Político-acadêmica, Programa de Iniciação ao Mundo do Trabalho, Programa Alimentação Estudantil, Programa de Atendimento aos Filhos dos Estudantes e Programa Moradia Estudantil. (CEPE/IFSC, 2010)

Considerando que o fator financeiro não é o único a ser observado como atuante na motivação pessoal, proporia-se aqui uma pesquisa sócio-histórico-econômica mais aprofundada relativa ao perfil do estudante dos cursos técnicos profissionalizantes subsequentes, com o objetivo de analisar se tais políticas estão sendo capazes de alcançar esta demanda presente no campus de Criciúma, ou se sua diferenciação dos alunos matriculados no ensino integrado faz com que acabem negligenciados em algum aspecto.

Tal suspeita é levantada pelo fato do Pnaes ser direcionado ao Ensino Superior e, apesar do Documento de Referência para Assistência Estudantil do Instituto Federal de Educação, Ciência e Tecnologia de Santa Catarina deixar claro que suas políticas foram pensadas com o objetivo de atender todas as modalidades de ensino, se sabe que os Institutos Federais possuem um foco na educação profissional de nível médio, prioritariamente integrada, à qual ficam garantidas $50 \%$ das vagas ofertadas, conforme art. 8ํ da Lei $\mathrm{n}^{\circ}$ 11.892. (BRASIL, 2008)

\section{ESTRATÉGIAS PEDAGÓGICAS APLICÁVEIS AO PROBLEMA DA EVASÃO}

Além das políticas de assistência estudantil, a própria instituição pode fazer uso de estratégias internas. Estas são capazes de minimizar os fatores agravantes do fenômeno da evasão e potencializar o sentido da escola para o aluno, aumentando sua sensação de pertencimento. Como ferramenta capaz de facilitar a conciliação entre trabalho e estudo é discutida a modalidade de educação à distância (EaD). Por outro lado, visando estreitar a relação entre aluno e instituição, são apresentadas as estratégias de reforço de vínculo e formação continuada.

Papalia, Olds\& Feldman (2006) apresentam um estudo realizado com 23 faculdades e universidades de 16 estados dos EUA, que relata o efeito positivo que o trabalho pode ter na vida do estudante ao ajudá-lo a organizar suas atividades. Porém Criar Educação, Criciúma, v. 6, nº1, julho/novembro 2016.- PPGE - UNESC 
quando este tempo de trabalho ultrapassa 15 ou 20 horas semanais os reflexos tornam-se negativos. Lembrando que sendo $96,23 \%$ dos alunos evadidos da amostra investigada no IFSC - campus de Criciúma, composta por alunos trabalhadores, se nota a importância de analisar alternativas de organização de tempo que possam harmonizar trabalho e estudo.

Conforme art. $1^{\circ}$ do decreto ํㅜ 5.622 a educação a distância se caracteriza como "modalidade educacional na qual a mediação didático-pedagógica nos processos de ensino e aprendizagem ocorre com a utilização de meios e tecnologias de informação e comunicação, com estudantes e professores desenvolvendo atividades educativas em lugares ou tempos diversos." Regulamentada também para modalidade de educação profissional técnica de nível médio e tecnológica de nível superior, conforme seu art. $2 \stackrel{0}{ }$. (BRASIL, 2005)

O próprio Plano de Desenvolvimento Institucional do IFSC (2009) apresenta a possibilidade de utilização desta modalidade como maneira de promover inclusão social, multiplicidade de oferta, inclusão digital e acessibilidade, além de "alcançar um público que em razão da distância ou rigidez dos horários, não consegue ter acesso aos cursos oferecidos na modalidade presencial." (IFSC, 2009, p.59)

O que nos leva a considerar a possibilidade de utilização desta ferramenta como meio de elevar os índices de permanência e êxito da grande demanda de alunos que apresentam problemas de incompatibilidade entre trabalho e estudo, problemas de deslocamento até o campus e problema de baixa renda. Vale salientar ainda a flexibilidade da modalidade, podendo ser utilizada de forma combinada, harmonizando com qualidade a modalidade presencial e à distância, requisitos do curso e necessidades dos alunos, possibilitando assim uma maleabilidade de horários sem que seperca a integração social da sala de aula, práticas laboratoriais e contato direto com o professor.

O uso das Tecnologias de Informação e Comunicação (TIC) estão cada vez mais disseminadas, não apenas na vida cotidiana, mas também no ambiente escolar, devido a sua capacidade de flexibilizar tempo e espaço, sua interatividade e estímulo da autonomia e autogestão de seus usuários. (ALMEIDA, 2003; ANDRADE \& PEREIRA, 2013). Para reforçar esta afirmativa, uma análise comparativaentre o primeiro censo do Anuário Brasileiro Estatístico de Educação Aberta e a Criar Educação, Criciúma, v. 6, nº1, julho/novembro 2016.- PPGE - UNESC 
Distância(ABED) com suas informações mais recentes, revela um aumento de 215 para 9376 cursos - autorizados e livres - oferecidos na modalidade EaD em instituições brasileiras. (ABED 2005; ABED, 2013)

Por meio dos dados levantados pelo Censo realizado pela ABED (2013) se pode perceber um índice de evasão escolar de cursos autorizados de educação à distância de 18,6\% em 2010, 20,5\% em 2011 e 11,74\% em 2012. Apesar do principal fator atuante para o processo de evasão ser a "falta de tempo para estudar e participar do curso (24\%)", ainda se percebe uma grande diferença entre as taxas de evasão dos cursos autorizados da EaD e dos cursos técnicos subsequentes presenciais oferecidos pelos Institutos Federais. Considerando ainda uma possibilidade de educação de modalidade combinada, poderia se tomar como base o índice de evasão de disciplinas EaD apresentados da seguinte maneira no mesmo censo: 17,6\% em 2011 e 3,1\% em 2012; representando um índice ainda mais promissor, frisando que a maior parte da amostra do anuário da ABED é composta também por alunos trabalhadores.

Andrade \& Pereira (2013) apresentam que a adesão aos programas federais de EaD pelos Institutos Federais iniciam uma nova etapa de educação profissionalizante onde ensino presencial e a distância possam se relacionar, gerando novas didáticas e abordagens pedagógicas, o germe de uma modalidade híbrida de educação. Tal panorama já aparece como uma realidade do IFSC - campus de Florianópolis, onde os professores começam a assimilar o método dialógico e cooperativo característico da EaD em detrimento ao simples repassar de conhecimento.

Quanto à importância da aplicação de novas estratégias pedagógicas capazes de dar suporte às necessidades mais subjetivas dos alunos, Guimarães \&Archangelo (2013), por exemplo, levam a teoria da psicanálise para dentro da sala de aula. Focando no conceito freudiano de transferência, apresentam que as primeiras relações da vida de um indivíduo formam a imago ${ }^{4}$ do pai, mãe e irmãos que permanecem ligadas aos afetos infantis mesmo durante a idade adulta, sendo que tais modelos internos acabam sendo transferidos para outras pessoas do convívio social do sujeito juntamente com toda a sua carga afetiva inconsciente. Concluem

\footnotetext{
${ }^{4}$ Imagem inconsciente e idealizada de um objeto, construída em idade precoce e carregada de valor afetivo.

Criar Educação, Criciúma, v. 6, nº1, julho/novembro 2016.- PPGE - UNESC
} 
então que estes afetos influenciam diretamente no aprendizado do aluno devido a relação que se estabelece entre si e o professor, sendo este, um depositário da imago idealizada capaz de facilitar ou bloquear o aprendizado.

Guimarães \&Archangelo (2013) relatam a experiência de aplicação deste princípio no Curso Superior de Tecnologia em Mecatrônica Industrial do IFSC - campus Florianópolis, que vinha sofrendo com altos índices de evasão, principalmente em seu primeiro módulo. O programa se desenvolveu através da aplicação da Entrevista de Acolhimento e Contrato de Trabalho como recursos de diagnóstico, reconhecimento, humanização e planejamento para o curso, aproximando coordenadoria e professores dos estudantes, lhes permitindo conhecer sua singularidade.

A relação de acompanhamento estabelecida cria um vínculo de respeito, transmitindo ao aluno a segurança para expressar suas dificuldades sem se sentir desamparado, o que leva o sujeito a procurar por orientação antes de tomar a decisão de abandonar a instituição. LaPlante(2014), por sua vez, diz que devido a influência do arquétipo familiar, alunos em situação de risco de evasão estão mais propensos a se envolverem nestas relações de cordialidade, se tais se apresentarem como justas e legítimas. Tal fato fora comprovado pelo controle dos índices de evasão do curso em questão no decorrer de três anos de aplicação do projeto, demonstrando expressiva redução de 51,2\% em $2007 / 1$ para $13,9 \%$ em 2009/2. (GUIMARÃES \& ARCHANGELO, 2013)

Maslow (1970) relata que algumas necessidades de um indivíduo podem estar presas a objetos simbólicos, de tal forma, como alvo de uma transferência de uma imago, o professor pode adquirir o potencial de suprir necessidades de segurança, amor e estima de seus alunos, ajudando-os a se manterem em equilíbrioe motivados a desenvolver autonomia, visão crítica e busca de auto-realização.

Não apenas para que ocorra uma maior aproximação entre professor e aluno, mas para que se possa haver compreensão das necessidades de ambos e, por consequência, uma constante atualização no processo ensino-aprendizagem, se faz necessária uma formação continuada que se estenda para além do saber específico, abrangendo também o aspecto pedagógico.

Criar Educação, Criciúma, v. 6, nº1, julho/novembro 2016.- PPGE - UNESC 
Ao se escolher um professor muitas vezes acaba se considerado apenas seu conhecimento e domínio sobre a matéria lecionada, o que pode caracterizá-los como "muito competentes no exercício de uma profissão (engenharia, direito, informática, odontologia, entre outras áreas), mas que não possuem formação pedagógica e não se ressentem de sua necessidade de valor" (LIRA \& SPONCHIADO, 2012, p.13) e, por consequência, possuem grande dificuldade de produzir aprendizagens significativas.

A distância entre docentes e pedagogos numa outra instituição de ensino pode até não ser tão grande, porém, de acordo com Andrade \& Pereira (2013, p.156-157) "no IFSC ela ganha proporções porque, de um lado, tem a equipe pedagógica formada por supervisores, orientadores e psicólogos educacionais e, do outro lado, um corpo docente formado, na sua maioria, por engenheiros e técnicos." Formando assim uma dicotomia que pode vir a interferir negativamente no trabalho interdisciplinar.

A formação continuada deve ser incentivada para que o docente possa refletir sobre si e sobre o mundo, desenvolvendo constantemente sua ética e aprimorando a prática educativa, assim transmitindo sua própria atitude aos seus alunos, tornandoos conscientes, transformadores e criadores, ao invés de simples "depósitos" de conteúdo. Tal professor precisa, primeiramente, despertar do condicionamento no qual pode estar preso, para posteriormente servir de orientador deste mesmo processo, sempre respeitando a autonomia, senso de estética e curiosidade de seu educando, auxiliando-os na inserção no mundo ao invés de se adaptarem a ele. (LIRA \& SPONCHIADO, 2013; FREIRE, 2003)

A constante atualização profissional vem ser lembrada neste ponto pelo seu potencial como ferramenta de união entre as possibilidades, até então levantadas, para se combater o alto índice de evasão escolar investigado no instituto Federal de Santa Catarina, campus de Criciúma. A compreensão e crítica do mundo e do ser humano ajudam o indivíduo e rever suas posturas, permitindo compreender o outro, aproximar-se e perceber suas necessidades. Dá-lhe conhecimento para utilização de novas tecnologias e metodologias de ensino, e conhecimento acerca das políticas de auxílio existentes, além da possibilidade de contribuição a partir da geração de novos conhecimentos.

Criar Educação, Criciúma, v. 6, nº1, julho/novembro 2016.- PPGE - UNESC 


\section{APRESENTAÇÃO DOS DADOS DA PESQUISA}

Foi repassada ao estagiário, pelo diretor do NUPE do campus de Criciúma, uma lista composta por 103 alunos possivelmente evadidos, elaborada com a ajuda dos coordenadores de cada respectivo curso. A relação abrangeu alunos dos módulos I, II e III do curso de Edificações e módulos I e II do curso de Eletrotécnica, possivelmente evadidos no período compreendido entre o primeiro semestre de 2013 até o mês de março de 2014, distribuídos conforme demonstra o Gráfico 1 Lista de Alunos Para Contato:

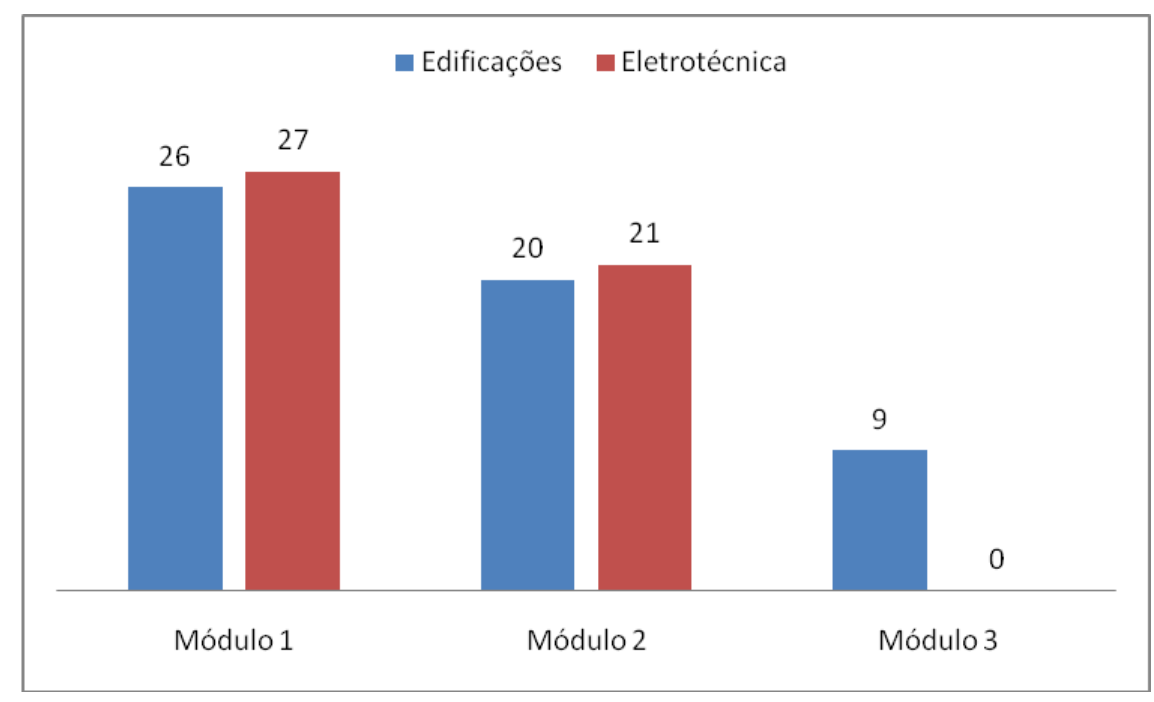

Gráfico 1 - Lista de Alunos Para Contato

Ao fim da pesquisa, dos 103 contatos propostos, obteve-se êxito de investigação em 73 dos casos. Utilizando-se de um formulário como instrumento de coleta de dados, preenchido pelo próprio estagiário a partir de entrevista semiestruturada por via telefônica,descobriu-se que entre este total: 20 alunos afirmaram ainda estar frequentando as aulas, 7 dos contatos confirmaram a retenção ${ }^{5}, 13$ alunos foram orientados para realização do trancamento de matrícula, 31 casos foram confirmados ou encaminhados para cancelamento e 2 estudantes se encontram em negociação com a coordenadoria.

\footnotetext{
${ }^{5}$ Trancamento do curso para casos de alunos que pretendem retornar aos estudos posteriormente.
}

Criar Educação, Criciúma, v. 6, no1, julho/novembro 2016.- PPGE - UNESC 
Dos 30 casos não contatados, 14 se deram por conta de falta ou erro de dados de contato no Registro Acadêmico e 16 por não atenderem as tentativas de ligaçõestelefônicas realizadas pelo estagiário, sendo que entre este total 5 alunos encontram-se em retenção. O fechamento desta etapa é apresentado no gráfico abaixo:
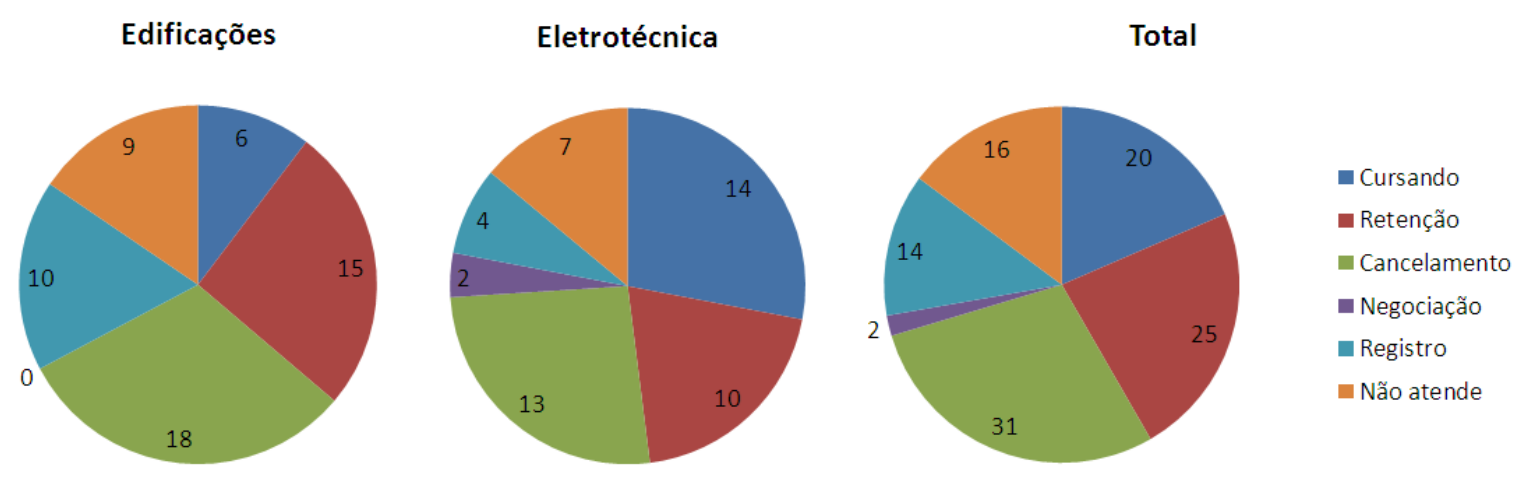

Gráfico 2 - Conclusão das Ligações

Direcionando para o objetivo da pesquisa, entre os 53 alunos entrevistados, distribuídos entre os módulos de Edificações e Eletrotécnica conforme o Gráfico 3 Lista de Alunos Entrevistados, 45 enquadram-se como sendo do sexo masculino e 8 do sexo feminino. Apenas $9,43 \%$ possuem ensino superior e, entre os graduados em nível médio, somente 3 pertenceram a rede privada de ensino.

Criar Educação, Criciúma, v. 6, nº1, julho/novembro 2016.- PPGE - UNESC 


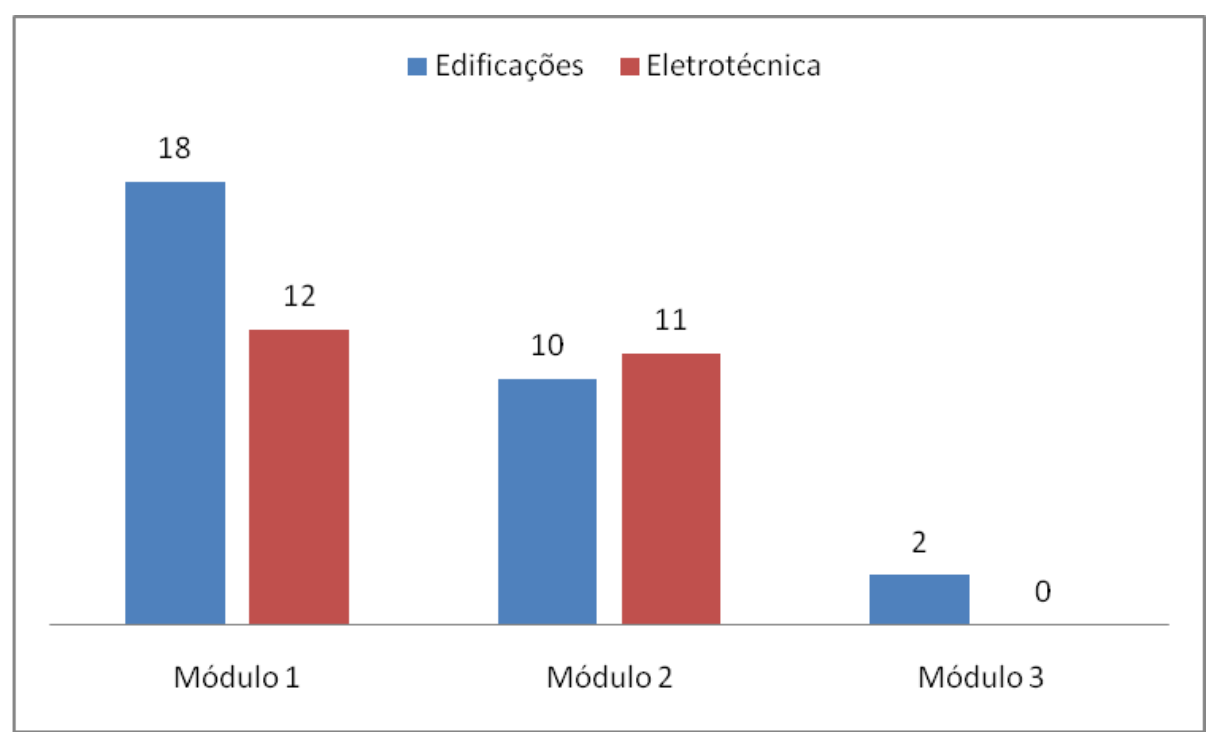

Gráfico 3 - Lista de Alunos Entrevistados

Quanto à faixa etária, conforme Gráfico 4 - Nascimento, a amostra aparece como predominantemente composta por adultos jovens com idade entre 20 e 29 anos e, em sua maioria, solteiros $(62,26 \%$ do total da amostra).

Criar Educação, Criciúma, v. 6, ํo1, julho/novembro 2016.- PPGE - UNESC 


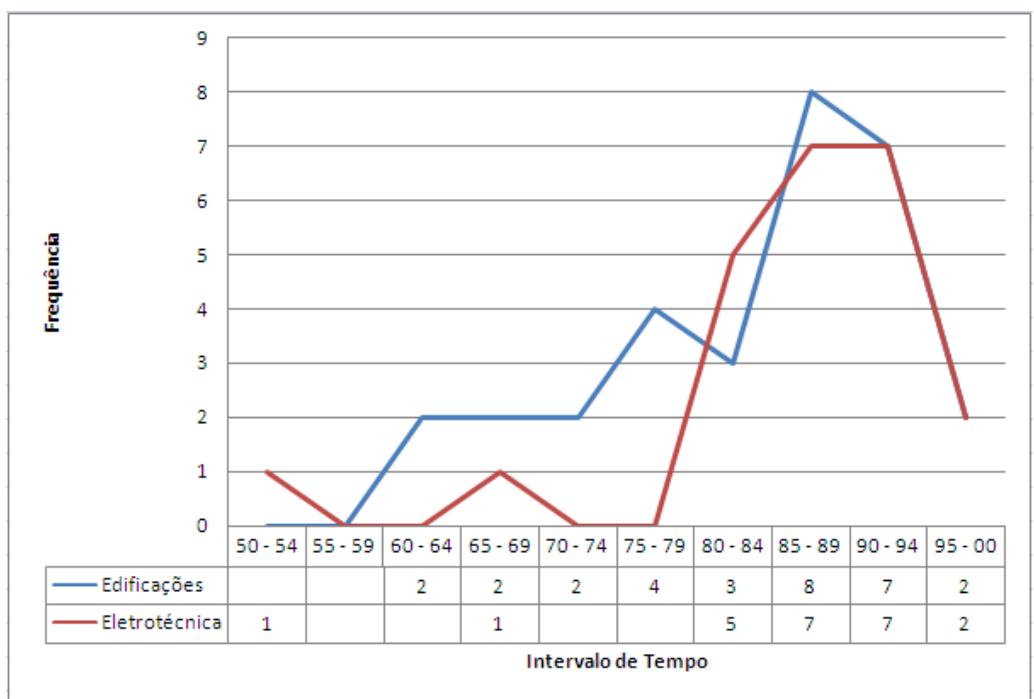

Gráfico 4 - Nascimento

Percebeu-se que $96,23 \%$ dos ex-alunos são trabalhadores, com renda familiar variando em um intervalo de 1 até 12 salários mínimos, com maior concentração entre 2 e 3 salários mínimos. Desconsiderando os 6 dos entrevistados que não possuíam este dado no Registro Acadêmico, a média aritmética ponderada dos valores finaliza em 3,38 salários mínimos por família.

Criar Educação, Criciúma, v. 6, no1, julho/novembro 2016.- PPGE - UNESC 


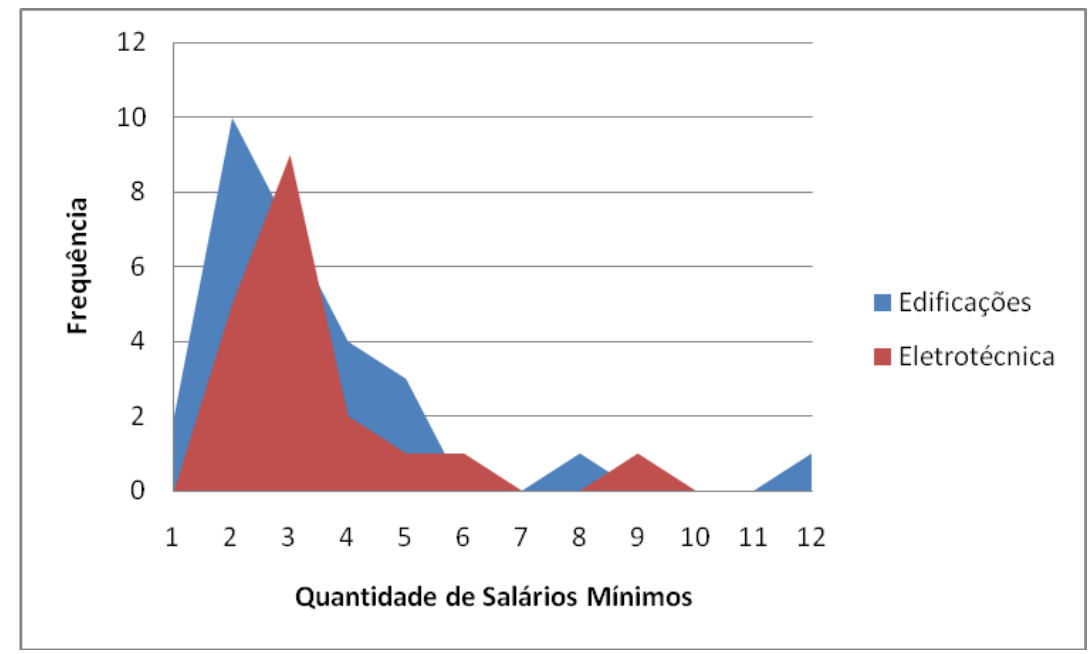

Gráfico 5 - Renda Familiar

A partir das 53 entrevistas realizadas, foi possível perceber 25 principais fatores atuantes no processo de evasão escolar destes ex-alunos. Dentro destes fatores computaram-se 91 apontamentos, registrando que $41,51 \%$ dos componentes da amostra indicaram mais de uma causa para o desligamento ou afastamento da instituição, indicando certa inter-relação entre os aspectos descobertos.

A frequência dada a cada um dos aspectos indicados como excludentes do processo de ensino-aprendizagem aparece no Gráfico 6 - Causas da Evasão.

Criar Educação, Criciúma, v. 6, no1, julho/novembro 2016.- PPGE - UNESC 


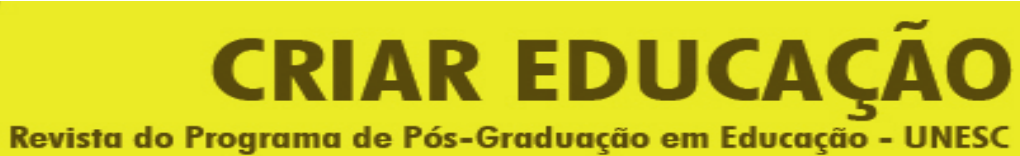

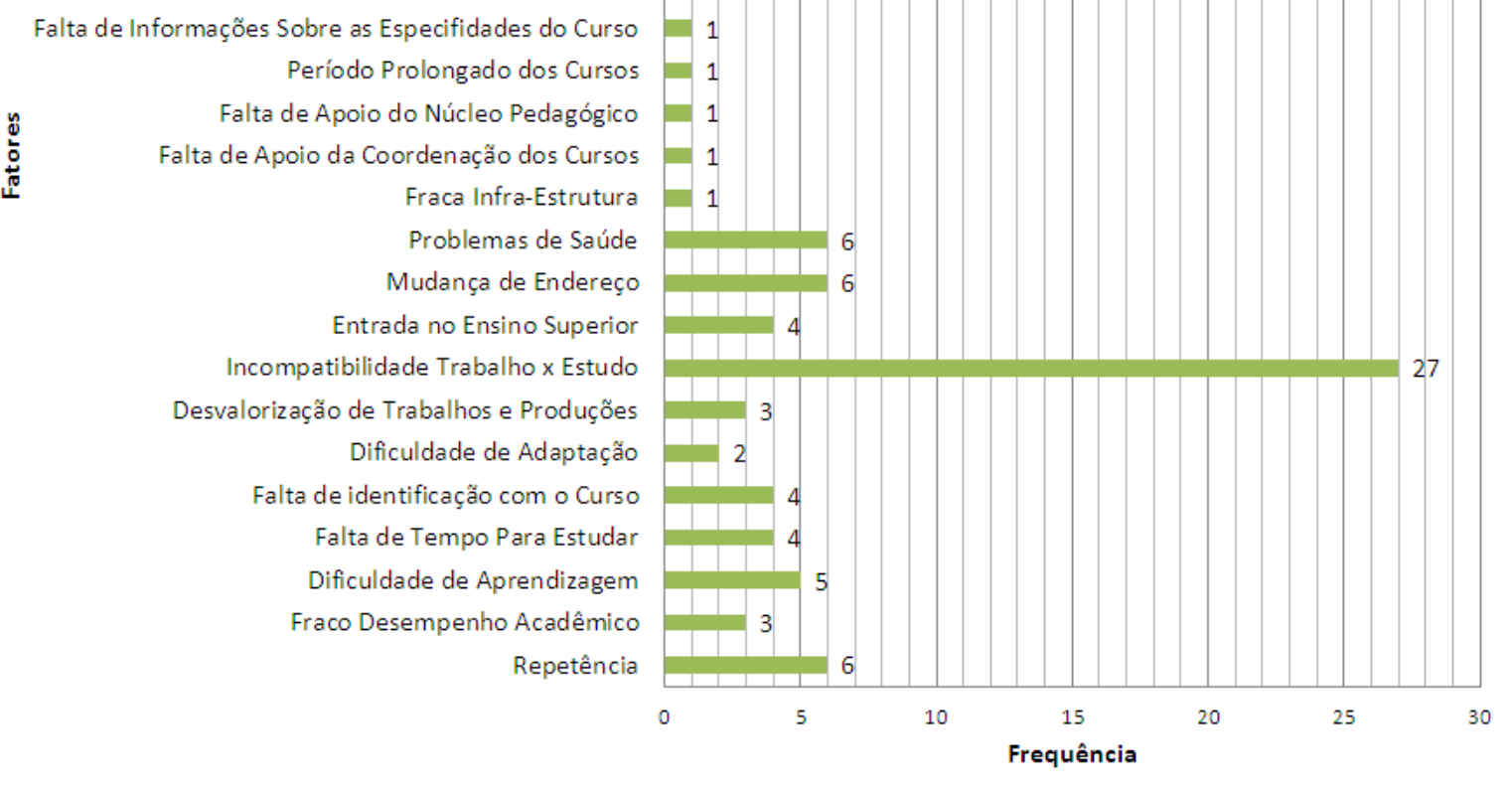

Criar Educação, Criciúma, v. 6, no1, julho/novembro 2016.- PPGE - UNESC 
Dos 29 alunos que apontaram como causa da evasão a incompatibilidade entre o trabalho e os estudos, falta de tempo para estudar e baixa renda - reunindo $36,3 \%$ dos apontamentos -, a maior parte afirma ter tomado tal atitude com o objetivo de priorizar a carreira profissional e a estabilidade social e financeira imediata que esta pode proporcionar. Foram citados principalmente a necessidade de cumprimento de horas extras para aumento da renda familiar ou como pré-requisito para manutenção do cargo, mudança de turno, carga horária estendida para cumprimento de tarefas acumuladas e/ou excessivas, mudança de endereço por migração de emprego e grande distância entre casa, escola e trabalho, como fatores desmotivacionais atuantes na interrupção dos estudos. Porém, apesar dos agravantes, 92\% desta parcela de entrevistados afirmou ter a intenção de retornar ao IFSC.

Apesar de apresentar o segundo maior índice de apontamentos acumulados (17,6\%) ao se reunir os indicadores repetência, dificuldade de aprendizagem, fraco desempenho acadêmico e dificuldade de adaptação, sob um mesmo grupo, estes foram indicados por apenas 7 estudantes, totalizando apenas $13,2 \%$ da amostra de alunos evadidos. Tais entrevistados relatam a dificuldade de acompanhar 0 aprendizado devido a falta de tempo para estudar fora do espaço escolar, debilidade de sua formação de nível médio e falta de auxílio de terceiros nos estudos.

Reunindo $12,1 \%$ das pontuações, o grupo composto pelos itens desvalorização de trabalhos e produções acadêmicas, problemas com o processo avaliativo, mau relacionamento com o professor, fraca infraestrutura, falta de apoio da coordenação dos cursos, falta de apoio do núcleo pedagógico e práticas pedagógicas, não apresenta alto nível de relevância para este estudo por se tratarem de casos pontuais relatados por apenas 4 ex-alunos que se sentiram prejudicados por alguns critérios de avaliação. Em contrapartida aos problemas relatados, foi ouvida uma série de elogios espontâneos à instituição como um todo, direcionados aos professores, equipe pedagógica e laboratórios, além de que, $77,4 \%$ da amostra total afirmam ter a intenção ou considerar a possibilidade de retornar ao IFSC futuramente.

Criar Educação, Criciúma, v. 6, nº1, julho/novembro 2016.- PPGE - UNESC 
Dos 7 alunos que comporam as estatísticas relacionadas a falta de identificação com o curso, entrada no ensino superior, período prolongado dos cursos e falta de informações sobre as especificidades do curso, 3 já se encontram matriculados em curso superior, 1 ingressou em curso técnico Pronatec e 1 está frequentando curso pré-vestibular, sobrando assim apenas 2 casos característicos de evasão.

Apesar do problema do deslocamento - englobando os fatores mudança de endereço e dificuldade de transporte - alcançar uma taxa de $12,1 \%$ dos apontamentos, a grande maioria de seus relatores relacionam tal problema a questão do trabalho, mudando-se de cidade por causa de um novo emprego ou sendo impossibilitados de chegar a tempo nas aulas por trabalharem a uma longa distância do Instituto.

Os casos restantes - falta de incentivo da família, motivos pessoais, alistamento no exército e despreparo devido ao fraco ensino básico - se tornam irrelevantes para a pesquisa por já estarem inclusos como fator correlacionado a algum dos grupos já apresentados e/ou por serem pontuais, com apenas uma marcação de cada caso.

\section{CONSIDERAÇÕES FINAIS}

A incompatibilidade entre as rotinas de trabalho e estudo se apresenta como um grande fator atuante no processo de evasão escolar, porém, mesmo não se tratando de um aspecto institucional, a escola possui ao seu alcance uma série de ferramentas capazes de facilitar a manutenção das necessidades mais básicas de seus alunos, para que estes, seguros de sua integridade, possam buscar o desenvolvimento e auto realização necessários para se tornarem, também, sujeitos transformadores.

O simples apontamento das possibilidades não é capaz de solucionar o problema, no entanto as reflexões presentes neste trabalho visam desafiar pesquisadores e instituições a avaliarem, de acordo com sua realidade, a aplicabilidade e efetividade das ferramentas e teorias expostas que, geralmente, se encontram presentes em seus próprios planos de ensino e desenvolvimento.

Estudos precisam ser desenvolvidos sobre a capacidade de abrangência das políticas de assistência estudantil, a eficácia de seu método seletivo e a capacidade Criar Educação, Criciúma, v. 6, no1, julho/novembro 2016.- PPGE - UNESC 
de suporte de seus recursos financeiros. Também acerca da aceitação e adaptação, pelos alunos e professores, para com as novas formas de ensino através de tecnologias e uso de ambientes virtuais. Além da importância da formação pedagógica dos professores de nível técnico, o nível de proximidade e compreensão existente entre alunos e professores e os reflexos desta relação no processo de ensino-aprendizagem.Por fim, considerando a relevância do problema da evasão escolar e o papel fundamental da instituição e seus colaboradores na atuação contra esta problemática, percebe-se que os temas abordados no presente artigo merecem discussão e podem ser de grande valia se abordados como parte do currículo na formação continuada para professores.

Criar Educação, Criciúma, v. 6, nº1, julho/novembro 2016.- PPGE - UNESC 


\section{REFERÊNCIAS}

ABED. Anuário brasileiro estatístico de educação aberta e a distância. 2005. São Paulo, 2005.

ABED. Relatório analítico da aprendizagem a distância no Brasil. 2012. Curitiba, 2013.

ALMEIDA, Maria Elizabeth Bianconcini de. Educação à distância na internet: abordagens e contribuições dos ambientes digitais de aprendizagem. Revista Educação e Pesquisa, São Paulo, v.29, n.2, p. 327-340, jul./dez. 2003.

ANDIFES. Plano nacional de assistência estudantil. 2007-2008. Brasília, 2010. Disponível em: < http://www.andifes.org.br/wpcontent/files_flutter/Biblioteca_071_Plano_Nacional_de_Assistencia_Estudantil_da_ Andifes_completo.pdf $>$. Acesso em: 19 jun. 2014.

ANDRADE, Luiz Antônio da Rocha; PEREIRA, Elisabete Monteiro de Aguiar. Educação a distância e ensino presencial: convergência de tecnologias e práticas educacionais. In: SCHNEIDER, Maria Clara Kashny; AGUILAR, Luis Enrique (orgs.). Tragetórias de educação profissional e tecnológica, vol.1, Florianópolis: IFSC, 2013, p.143-163.

BARBIERI, Fabianaet al. Jovens estudantes trabalhadores. In: EDUCERE, 5., 2005, Curitiba. Anais... Curitiba: Pontifícia Universidade Católica do Paraná, 2005. p.949960.

BRASIL. Tribunal de Contas da União. Acórdão 506/2013. Plenário. Relator: José Jorge. Sessão de 13/03/2013. Diário Oficial da União. Brasília, DF, 2013.

BRASIL. Lei no 11.892, de 29 de dezembro de 2008. Institui a Rede Federal de Educação Profissional, Científica e Tecnológica, cria os Institutos Federais de Educação, Ciência e Tecnologia, e dá outras providências. Diário Oficial [da] República Federativa do Brasil.

BRASIL. Decreto no 5.622, de 17 de dezembro de 2005. Regulamenta o art. 80 da Lei o 9.394 , de 20 de dezembro de 1996, que estabelece as diretrizes e bases da educação nacional. Diário Oficial [da] República Federativa do Brasil.

CASTRO, Tatiane Lage de; DORE, Rosemary; SALES, Paula Elizabeth Nogueira. Educação profissional e evasão escolar: estudo e resultado parcial de pesquisa sobre a rede federal de educação profissional e tecnológica de Minas Gerais. In: COLILÓQUIO INTERNACIONAL DE EDUCAÇÃO PROFISSIONAL E EVASÃO ESCOLAR, 3., 2013, Anais... Pampulha: Universidade Federal de Minas Gerais. Disponível em:

Criar Educação, Criciúma, v. 6, nº1, julho/novembro 2016.- PPGE - UNESC 
$<$ https://drive.google.com/?tab=mo\&authuser=0\#folders/0B1 yMsJLydsHnNmo2WIBq Vml2WmM>. Acesso em 31 mar. 2014.

CEPE/IFSC. Proposta de Regulamentação do PAEVS. v.2. 2014. Disponível em: http://www.ifsc.edu.br/arquivos/assistenciaestudantil/VERS\%C3\%830_2_Document o_base_PAEVS.pdf>. Acesso em 08 jul. 2014.

CEPE/IFSC. Regulamentação da assistência estudantil. Decreto $n \div 001 / 2010$ de 30 de novembro de 2010. Disponível em: <www.ifsc.edu.br/ass-legislacao>. Acesso em 26 jun. 2014.

CEPE/IFSC. Regulamentação do programa de atendimento básico e programa de auxílio complementar. Decreto no 54 de 12 de abril de 2011. Disponível em: $<w w w . i f s c . e d u . b r / a s s-l e g i s l a c a o>$. Acesso em 26 jun. 2014.

DORE, Rosemay; LÜSCHER, Ana Zuleima. Política educacional no Brasil: educação técnica e evasão escolar. Revista Brasileira de Pós-Graduação, Brasília, supl. 1, v.8, p.147-176, dez. 2011.

DORE, Rosemary; LÜSCHER, Ana Zuleima. Permanência e evasão na educação técnica de nível médio em Minas Gerais. Cadernos de Pesquisa, São Paulo, v.41, n.144, set./dez. 2011. Disponível em: <http://educa.fcc.org.br/scielo.php?pid=S0100$15742011000300007 \&$ script=sci_arttext>. Acesso em 31 mar. 2014.

FREIRE, Paulo. Conscientização: teoria e prática da libertação: uma introdução ao pensamento de Paulo Freire.3.ed. São Paulo: Centauro, 2001, 102 p.

FREIRE, Paulo. Ensinar não é transferir conhecimento. In:

Pedagogia da autonomia: saberes necessários à prática educativa. 28.ed. São Paulo: Paz e Terra, 2003, p.21-35.

GUIMARÃES, Sandra Lopes; ARCHANGELO, Ana. O conceito psicanalítico de transferência e a diminuição da evasão escolar em um curso superior de tecnologia. In:SCHNEIDER, Maria Clara Kashny; AGUILAR, Luis Enrique (orgs.). Tragetórias de educação profissional e tecnológica, vol.2, Florianópolis: IFSC, 2013, p.191222.

IFSC. Plano de desenvolvimento institucional. 2009-2013. Florianópolis, 2009. Disponível em: <www.ifsc.edu.br/ass-legislacao>. Acesso em 26 jun. 2014.

IFSC. Documento referência para a assistêcia estudantil do Instituto Federal de Educação, Ciência e Tecnologia de Santa Catarina. 2010. Florianópolis, 2010. Disponível em: <www.ifsc.edu.br/ass-legislacao>. Acesso em 26 jun. 2014.

INEP / MEC. Sinopse estatística da educação básica. 2007. Disponível em: $<$ http://portal.inep.gov.br/basica-censo-escolar-sinopse-sinopse>. Acesso em: 19 jun. 2014.

Criar Educação, Criciúma, v. 6, no1, julho/novembro 2016.- PPGE - UNESC 
LaPlante, Matthew D. Obtendo sim, e sim, e sim outra vez: a adaptação de princípios de persuasão para a recuperação de evadidos e a abordagem do programa "Nenhum Evadido" para o reengajamento de indivíduos. Tradução de Rosemary Dore. Disponibilizado em:Capacitação sobre assistência estudantil: integrar, agregar saberes e compartilhar práticas, Pelotas, 2014.

LAUDARES, João Bosco. Políticas públicas para educação profissional e aportes teóricos para a pesquisa sobre evasão escolar. In: COLÓQUIOINTERNACIONALSOBREEDUCAÇÃOPROFISSIONALEEVASÂOESCO LAR, 1., 2009, Minas Gerais. Anais... Minas Gerais: Faculdade de Educação da Universidade Federal de Minas Gerais, 2009, s/p.

LIRA, Daiane; SPONCHIADO, Denise Aparecida Martins. A formação pedagógica do profissional docente no ensino superior: desafios e possibilidades. Revista Perspectiva, Erechim, v.36, n.136, dez. 2012, p.7-15.

MASLOW, Habraham H. Motivation and personality.2.ed. New York: Harper \& Row, 1970. 363 p.

SIMÕES, Carlos Artexes. A educação técnica e a escolarização de jovens trabalhadores. In: Educação profissional e tecnológica no Brasil contemporâneo: desafios, tensões e possibilidades. Porto Alegre: Artmed, 2010, p.96-119.

STOLTZ, Tania. Teoria da motivação humana. In: Saúde psicológica sob a perspectiva de Abraham Maslow. Campinas, SP: Alínea, 2000. p. 16-26. 